\title{
Characteristics of headache disorders, according to ICHD-III in an outpatient headache clinic in Sohag Governorate, Egypt
}

\author{
Al-Amir Bassiouny Mohamed(0)
}

\begin{abstract}
Background: Headache disorders are rated among the ten most disabling conditions around the world. The primary headache disorders are more common that of secondary headache. The third edition of the International Classification of Headache Disorders (ICHD-III) is considered as a helpful tool for classification and diagnosis of different headache disorders.

Methods: This is a cross-sectional study that included 500 patients who attended to the headache clinic, between May 2018 and April 2019. Arabic version of headache questionnaire was used to characterize headache, according to ICHD-III.

Results: Primary headache disorders were found in $89 \%$ (most of them is episodic in nature $76.2 \%$ ), secondary headache disorders in about $10 \%$, and painful cranial neuropathy was present in $0.8 \%$. Primary headache associated with sexual activity was present in $1 \%$ of the total number of headache patients, and episodic cluster headache was found in $0.8 \%$. Medication overuse headache $(\mathrm{MOH})$ was the most frequent secondary headache with $2.8 \%$ of the total number of headache patients, and when overlaps with chronic migraine or chronic tension type of headache $(\mathrm{TTH})$, the percent was $12.8 \%$ and $8.8 \%$ respectively. Male to female ratio was 1:3, 3:5, and 1:1 in primary headache, secondary headache, and painful cranial neuropathy respectively. Simple analgesia was the most common abortive therapy (44.8\%) while the antidepressants were the most common preventive treatment (17\%).

Conclusion: This study estimates the frequency and characterizes different headache disorders, according to ICHDIII in an outpatient headache clinic at Sohag Governorate, Egypt.
\end{abstract}

Keywords: Headache ICHD-III, Arabic, Questionnaire

\section{Introduction}

Headache disorders are rated among the ten most incapacitating conditions worldwide with a global prevalence of $47 \%[1,2]$, and it may cause a significant social and economic burden [3]. The headache can be classified to primary headache disorders which include migraine, tension-type headache (TTH), and cluster headache, and

Correspondence: amirmohamed3636@gmail.com

Department of Neurology and Psychological Medicine, Sohag University Hospital, Sohag University, El Kawaser, P.O. Box 82524, Sohag, Egypt less common secondary type of headache which may be due to intracranial neoplasms, epileptic seizures, or intracranial infections $[4,5]$. A recent meta-analysis indicates that migraine is highly prevalent worldwide, with a prevalence to be $11.6 \%$ on the community level [6]. In a study conducted with participants from Eastern Mediterranean Region (EMR), Vosoughi and colleagues [7] emphasized the fact that primary headache disorders are a large cause of disability in this region and highlighted the priority of management and preventive measures to decrease the burden of headache in this region [7]. In 
Egypt, a population-based study conducted in Fayoum Governorate revealed that the 1-year headache prevalence was $51.4 \%$, and the most common primary headache subtype was episodic tension type headache $(24.5 \%)$, followed by episodic migraine (17.3\%) [8]. Similarly, a study conducted in Saudi Arabia revealed that tension headache was also the commonest primary headache with a prevalence of $9.5 \%$ then migraine with prevalence 5.0\% [9]. In addition to a study conducted in Qatar and based on face-to-face questionnaire, it was reported that migraine was present in $7.9 \%$ [10]. So, the results of epidemiological studies of headache disorders are still inconsistent, particularly in Arab countries in spite of its significant burden and disability.

Worldwide estimate of secondary headache is $18 \%$ of headache patients [11] with 1-year prevalence of $2.1 \%$ in a population-based study [5] and $12.9 \%$ of headache patients when the epidemiological studies conducted in tertiary centers [12]. After publication of ICHD-III in 2018, it was widely accepted for classification and diagnosis of headache disorders [13]. In developing countries particularly Egypt, headache is still poorly managed because of several reasons, including insufficient patient education, over-the-counter self-medications, and improper understanding of impact of headache on patient's quality of life $[8,14]$. The aim of this hospital-based cross-sectional study is to investigate the frequency and characteristics of different types of headache in the light of recent headache classification namely ICHD-III.

\section{Methods}

Participants in this cross-sectional study were recruited from the outpatient headache clinic, between May 2018 and April 2019. The hospital is a tertiary center serving a wide geographical area. Sohag is one of the governorates of Egypt. It is located in the southern part of the country (Upper Egypt) and covers a stretch of the Nile Valley. According to population estimates, in 2015, the majority of residents in the governorate lived in rural areas, with an urbanization rate of only $21.4 \%$. Of the approximately 4,603,861 residents in the governorate in $2015,3,628,543$ lived in rural areas and 985,318 in urban areas [15].

The sample $[n=500,131$ males $(26.2 \%)$ and 369 females (73.8\%)] consisted of patients complaining of headache. Each patient was subjected to full medical and neurological evaluation including history of precipitating factors for each headache attack, comorbid medical conditions, and educational level based on the International Standard Classification of Education (ISCED) [16].

We used the Arabic version of headache questionnaire [17] which was completed by patients, and those who are illiterate were helped by a neurologist in the outpatient headache clinic. This questionnaire is composed of two parts: the first part included demographic, personal, and medical aspects (age, gender, education, marital status, occupation, and place of living, contraceptive pill uses, smoking, hypertension, and other relevant medical disorders). The second part of the questionnaire included questions designed to define the nature and assess patterns of the headache including onset, duration, frequency, site, side-unilateral/bilateral, associated symptoms, and precipitating factors. Each type of headache was diagnosed according to most updated criteria of the ICHD-III [13] and classified into 14 different subgroups. Subgroups 1 to 4 were primary headaches, including migraine, TTH, trigeminal autonomic cephalgias (TACs), and the other primary headache. TACs are subdivided into cluster headache, paroxysmal hemicrania, and short-lasting unilateral neuralgiform headache attacks which include [short-lasting unilateral neuralgiform headache attacks with conjunctival injection and tearing (SUNCT) and short-lasting unilateral neuralgiform headache attacks with cranial autonomic symptoms (SUNA)]

Subgroups 5 to 12 were secondary headaches which are consequences of head and/or neck trauma; cranial or cervical vascular disorder; non-vascular intracranial disorder; substance or its withdrawal; infection; disorders of hemostasis; disorders of facial structures (disorders of the eyes, ears, nose, or paranasal structures), cranial structures (cranial bone, jaw disorders), or cervical structures (cervicogenic headache); and lastly psychiatric disorders. Brain computed tomography scan (Siemens Somatom Emotion, 16-CT scanner, Germany) and/or magnetic resonance imaging (Siemens MRI Essenza Machine, 1.5 Tesla, Germany) was done for patients with suspected intracranial lesions.

Subgroup 13 corresponds to painful cranial neuropathies and other facial pain. If the headache could not be accurately categorized as either primary or secondary, it was classified as subgroup 14 (unspecified or not elsewhere classified headaches). Patients with unclassified headache disorders were excluded from the study to accurately estimate the percentage of primary and secondary headache disorders. Patients who reported headaches at a frequency of more than 15 days/month over a period of 3 months were classified as chronic headache which include chronic migraine $(\mathrm{CM})$, chronic tensiontype headache $(\mathrm{CTTH})$, medication overuse headache $(\mathrm{MOH})$, new daily persistent headache (NDPH), chronic paroxysmal hemicrania, SUNA, or hemicrania continua (HC). Participants who reported headache $\geq 15$ days/ month with regular overuse for $>3$ months of one or more acute/symptomatic treatment drugs were diagnosed to have $\mathrm{MOH}$. The term probable in a specific headache category means headache is not fulfilling all the criteria in this category for example ICHD-III, coded 


\section{ICHD-III headache groups}

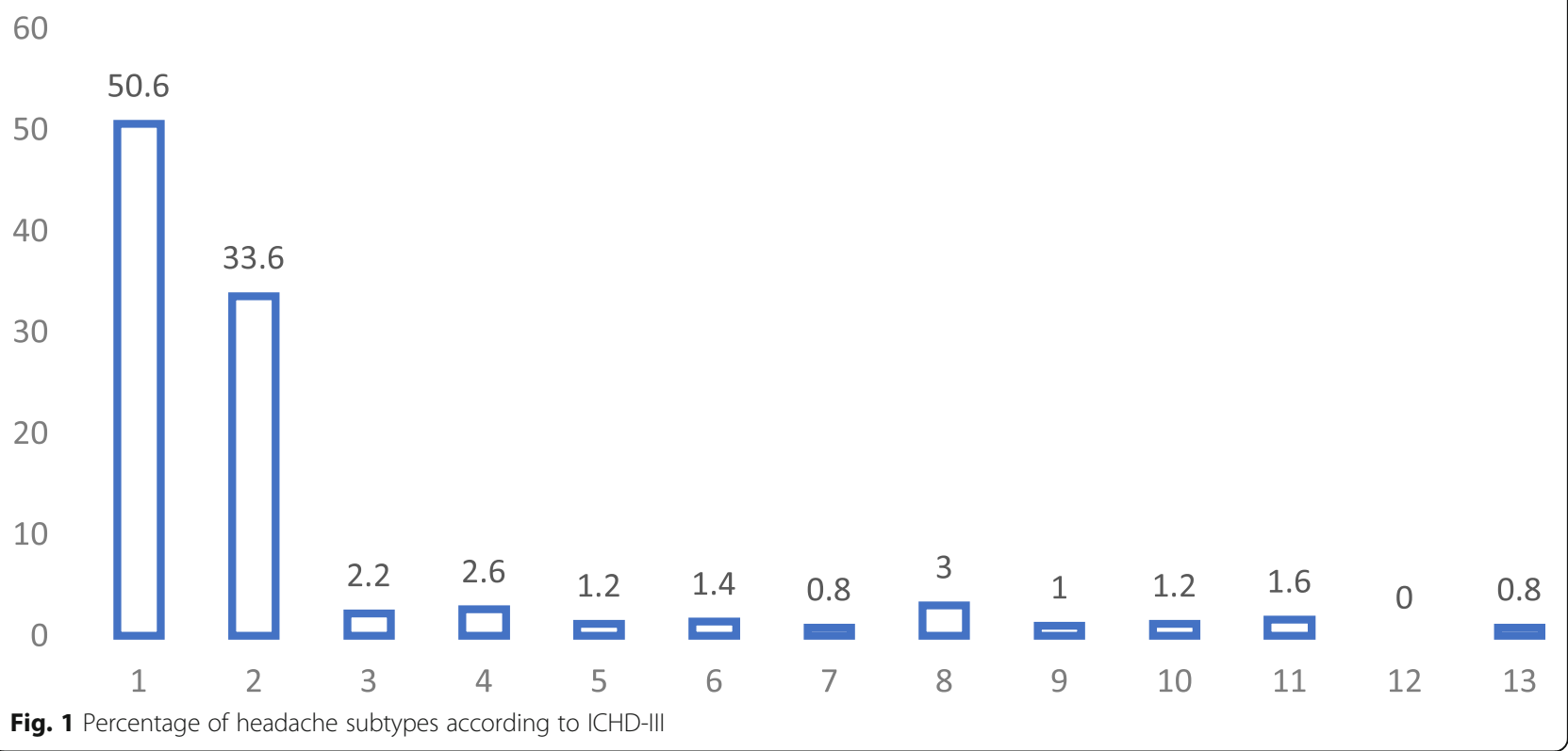

probable migraine without aura when the participant has had fewer than five attacks of headache [13]. The study was approved by the Ethical Committee on Research Involving Human Subjects at the University of Sohag on March 2018, and informed written consent was taken from each patient before the study.

The statistical analysis was performed using the Statistical Package for the Social Sciences for Windows (SPSS
20.0, IBM Corp., Armonk, NY, USA). Simple descriptive analysis in the form of means and standard deviations was calculated from numerical data. The prevalence was expressed in percentage. Non-parametric tests (chisquare) were used to find its association with other factors. The Student $t$ test was used to compare the continuous variables. A two-way between-groups analysis of variance was conducted to explore the impact of sex and

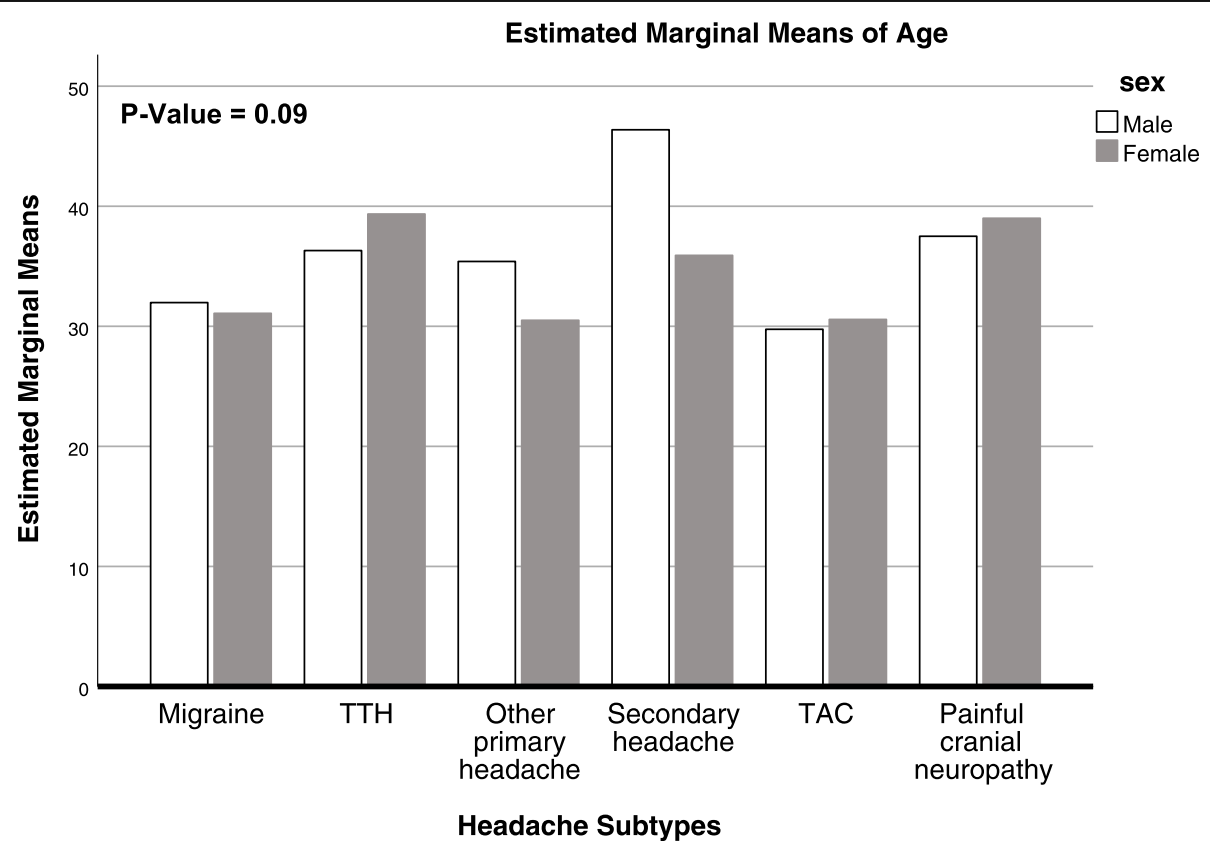

Fig. 2 Mean age for males and females in different headache subtypes 
Table 1 Socio-demographic characteristics of the participants

\begin{tabular}{|c|c|}
\hline Variables & Frequency \\
\hline Age (years, mean $\pm S D$ ) & $34.8 \pm 13$ \\
\hline \multicolumn{2}{|l|}{ Gender } \\
\hline Male & $131(26.2)$ \\
\hline Female & $369(73.8)$ \\
\hline \multicolumn{2}{|l|}{ Residence } \\
\hline Rural & $209(41.8)$ \\
\hline Urban & $291(58.2)$ \\
\hline \multicolumn{2}{|l|}{ Educational level } \\
\hline Illiterate & $171(34.2)$ \\
\hline Primary education & $72(14.4)$ \\
\hline Lower secondary & $106(21.2)$ \\
\hline Upper secondary & $108(21.6)$ \\
\hline Post-secondary education & $10(2.0)$ \\
\hline Short-cycle tertiary education & $29(5.8)$ \\
\hline Bachelor or equivalent & $4(0.8)$ \\
\hline \multicolumn{2}{|l|}{ Occupation } \\
\hline Not working & $27(5.4)$ \\
\hline Employee & $9(1.8)$ \\
\hline Student & 68 (13.6) \\
\hline Housewife & $295(59.0)$ \\
\hline Farmer & $38(7.6)$ \\
\hline Manual worker & $21(4.2)$ \\
\hline Teacher & $6(1.2)$ \\
\hline Seller & $18(3.6)$ \\
\hline Religious worker & $2(.4)$ \\
\hline Nurse or hospital technician & $8(1.6)$ \\
\hline Secretary & $2(.4)$ \\
\hline Driver & $2(0.4)$ \\
\hline Barber & $2(0.4)$ \\
\hline Food worker & $2(0.4)$ \\
\hline \multicolumn{2}{|l|}{ Marital status } \\
\hline Single & $129(25.8)$ \\
\hline Married & $357(71.4)$ \\
\hline Widow & $12(2.4)$ \\
\hline Divorced & $2(0.4)$ \\
\hline
\end{tabular}

age on different headache disorders with post hoc comparisons using the Tukey test. $P \leq 0.05$ was considered statistically significant.

\section{Results}

A sum of 500 headache patients was enrolled in this study and classified according to ICHD-III (Figs. 1 and 2). The participants' age ranged from 11 to 78 years with a mean age of $34.8 \pm 13$ years. The urban residency was $58.2 \%$, while rural residency was found in $41.8 \%$ (Table 1 ). The socio-demographic characteristics of the participants and precipitating factors of headache are shown in Table 1.

Primary headache (groups 1 to 4 of ICHD-III) was present in $89 \%$ of total participants, secondary headaches (groups 5 to 12) were present in $10.2 \%$, and painful cranial neuropathies (group 13) were present only in $0.8 \%$ (Table 2).

Because of the availability, simple analgesia was the most common abortive therapy (44.8\%) while the antidepressants were most commonly used as preventive treatment (17\%) in headache disorders as they are used in both migraine and TTH (Table 2).

Among primary headache, migraine was the most prevalent subtype (50.6\%), then TTH (33.6\%), and lastly painful cranial neuropathy $(0.8 \%)$ (Table 3$)$.

Sixty six percent of the total migraine participants have fulfilled the criteria for migraine without aura (including probable migraine without aura) while migraine with aura and chronic migraine were present in 13.8\% and $19.7 \%$ respectively (Table 3 ).

The frequency of different headache subtypes in males and females is shown in Table 3.

Male to female ratio was 1:3, 3:5, and 1:1 in primary headache, secondary headache, and painful cranial neuropathy respectively (Table 3 ).

Gender and age distribution in different headache subtypes is shown in Table 3.

Episodic and chronic headache was present in $76.2 \%$ and $23.8 \%$ respectively of the participants (Table 3 ). The percent of chronic headache in males was $30.5 \%$ while in females was $21.4 \%$ with $P$ value 0.03 .

Most of the patients with $\mathrm{MOH}$ have chronic migraine and chronic TTH with $12.8 \%$ and $8.8 \%$ respectively (Table 3).

\section{Discussion}

The prevalence of headache disorders, including migraine, tension-type headache, and $\mathrm{MOH}$, is high [18]. In population-based studies, migraine was found in 9.6 to $24.6 \%$, and 1 -year prevalence of $\mathrm{TTH}$ is in a wide range between 15 and $90 \%$. In an Egyptian study conducted in Fayoum Governorate, the observed 1-year prevalence of migraine and episodic TTH was 17.3 and $24.5 \%$ respectively [8]. In our series, we found that primary headache was present in $89 \%$, while secondary headache in $10.2 \%$ and painful cranial neuropathy in $0.8 \%$, and these results are in line with Guerrero and colleagues [19] who reported that primary headaches was present in $77.1 \%$ and secondary headaches in $10.9 \%$. Among the total headache participants, we found that the percent of migraine and TTH was $50.6 \%$ and $33.6 \%$ respectively. The percent of other primary headache and TACs was $2.6 \%$ and $2.2 \%$ 
Table 2 Headache characteristics

\begin{tabular}{|c|c|}
\hline Variables & Frequenc \\
\hline \multicolumn{2}{|l|}{ Headache subtypes } \\
\hline The primary headaches & $445(89)$ \\
\hline The secondary headaches & $51(10.2)$ \\
\hline $\begin{array}{l}\text { Painful cranial neuropathies, other facial pain and } \\
\text { other headaches }\end{array}$ & $4(0.8)$ \\
\hline \multicolumn{2}{|l|}{ Comorbid conditions } \\
\hline No comorbid conditions & $484(97.6)$ \\
\hline Hypertension (HTN) & $12(2.4)$ \\
\hline Diabetes mellitus (DM) & $2(.4)$ \\
\hline Hypothyroid & $1(.2)$ \\
\hline Hepatitis $C$ virus & $1(0.2)$ \\
\hline Headache that awakens the patient from sleep & $193(38.6)$ \\
\hline Family history of migraine & $20(4)$ \\
\hline Use caffeinated substances & $114(22.8)$ \\
\hline Past history of motion sickness & $35(7)$ \\
\hline \multicolumn{2}{|l|}{ Precipitants } \\
\hline No precipitating factors & $11(2.2)$ \\
\hline Odors & $90(18.0)$ \\
\hline Exercise & $8(1.6)$ \\
\hline Too little sleep & $63(12.6)$ \\
\hline Too much sleep & $46(9.2)$ \\
\hline Alcohol & $2(0.4)$ \\
\hline Fatigue & $65(13.0)$ \\
\hline Sunshine & $15(3.0)$ \\
\hline Cold days & $6(1.2)$ \\
\hline Oral contraceptive pills (OCP) & $5(1.0)$ \\
\hline Loud noises & $25(5.0)$ \\
\hline Anxiety or stress & $153(30.6)$ \\
\hline Bright lights & $5(1.0)$ \\
\hline Sexual activity & $5(1.0)$ \\
\hline \multicolumn{2}{|l|}{ Abortive treatment } \\
\hline Not using any drugs & $76(15.2)$ \\
\hline Simple analgesia including paracetamol and NSAID & $224(44.8)$ \\
\hline Using more than one type of simple analgesia & $179(35.8)$ \\
\hline $\begin{array}{l}\text { Selective 5-hydroxytryptamine (5HT) receptor agonists } \\
\text { (Triptans) }\end{array}$ & $16(3.2)$ \\
\hline Vasoconstrictors like ergot preparations & $5(1.0)$ \\
\hline Preventive treatment & () \\
\hline Not using any drugs & 98 (19.6) \\
\hline Simple analgesia including paracetamol and NSAID & 79 (15.8) \\
\hline Using more than one type of simple analgesia & $74(14.8)$ \\
\hline $\begin{array}{l}\text { Selective 5-hydroxytryptamine }(5 \mathrm{HT}) \text { receptor agonists } \\
\text { (Triptans) }\end{array}$ & $2(0.4)$ \\
\hline Vasoconstrictors like ergot preparations & $5(1.0)$ \\
\hline Antidepressants including amitriptyline and SSRI's & $85(17.0)$ \\
\hline
\end{tabular}

Table 2 Headache characteristics (Continued)

\begin{tabular}{ll}
\hline Variables & Frequency \\
\hline Antiepileptic agents & \\
Topiramate & $51(10.2)$ \\
Valproate & $21(4.2)$ \\
Carbamazepine & $14(2.8)$ \\
Antihypertensive & \\
Propranolol & $31(6.2)$ \\
Angiotensin-converting enzyme (ACE) inhibitors & $8(1.6)$ \\
Natural remedies (like Feverfew) & $16(3.2)$ \\
Multivitamin preparations & $5(1.0)$ \\
Chlorphenamine (nasal decongestant) & $11(2.2)$
\end{tabular}

NSAID non-steroidal anti-inflammatory drugs, SSRI's selective serotonin reuptake inhibitor

respectively. These results are consistent with those obtained from previous studies [20-24].

Pedraza and colleagues [25] reported that primary headache was present in $72 \%$ and secondary headache in $12 \%$, and among the primary headache group, migraine was present in $53 \%$, TTH in $10.5 \%$, TACs in $2.5 \%$, and other types of primary headache were present in $5.9 \%$, and they explained the low rate of TTH in their series by the lower impact of TTH on the patients, and few patients seek medical consultation for their headaches [25].

In a Hungarian study conducted on 327 patients, primary headache migraine was found in $42 \%$, TTH in $31 \%$, cluster headache in $1 \%$, and $26 \%$ had a combination headache [22]. Many previous studies documented that migraine is the most frequently assigned diagnosis in specialist clinics or headache units [12, 25-28].

Although some previous studies reported that TTH is the most common type of primary headache all over the world [1], migraine was the most common presentation in our series, and this may be explained by the underrecognition of TTH by patients and health practitioners for its less disability than migraine.

In contrast, a Turkish study was conducted in 245 of headache patients and revealed that TTH was present in $70 \%$ and migraine only in $44.9 \%$, [29] and this difference may be explained by a relatively small number of patients and different methodology as they used the ICHD-II criteria.

We reported that only $2.2 \%$ of total patients corresponds to TACs which is in line with the results obtained by Guerrero and colleagues [19] who reported that TACs were present in $2.6 \%$ of the patients and lower than that obtained by Dong and colleagues [12] who reported $5.3 \%$ of total patients were classified into TAC which may be explained by regional and racial reasons. 
Table 3 Frequency of headache subtypes between male and female

\begin{tabular}{|c|c|c|c|c|c|}
\hline Headache subtypes & Total & Males $(N=131)$ & Females $(N=369)$ & Male:female ratio & $P$ value \\
\hline Primary & 445 & $110(84 \%)$ & $335(90.8 \%)$ & $1: 3$ & \\
\hline Migraine & 253 & 75 & 178 & $3: 7$ & 0.1 \\
\hline Migraine without aura & 150 & $38(29.0 \%)$ & $112(30.4 \%)$ & & \\
\hline Chronic migraine & 50 & $18(13.7 \%)$ & $32(8.7 \%)$ & & \\
\hline Probable migraine without aura & 18 & $4(3.1 \%)$ & $14(3.8 \%)$ & & \\
\hline Migraine with visual aura & 15 & $4(3.1 \%)$ & $11(3.0 \%)$ & & \\
\hline Migraine with sensory aura & 13 & $7(5.3 \%)$ & $6(1.6 \%)$ & & \\
\hline Probable migraine with aura & 4 & $3(2.3 \%)$ & $1(0.3 \%)$ & & \\
\hline Migraine with brainstem aura & 3 & $1(0.8 \%)$ & $2(0.5 \%)$ & & \\
\hline Episodic migraine & $203(40.6)$ & $57(43.5)$ & $146(39.5)$ & & 0.3 \\
\hline Chronic migraine & $50(10)$ & $18(13.7)$ & $32(8.6)$ & & \\
\hline Tension-type headache & 168 & $26(19.8 \%)$ & $142(42.3 \%)$ & $1: 5$ & 0.004 \\
\hline Frequent episodic TTH associated with PT & 72 & $12(9.2 \%)$ & $60(16.3 \%)$ & & \\
\hline Frequent episodic TTH not associated with PT & 60 & $8(6.1 \%)$ & $52(14.1 \%)$ & & \\
\hline Chronic TTH associated with PT & 20 & $4(3.1 \%)$ & $16(4.3 \%)$ & & \\
\hline Chronic TTH not associated with PT & 8 & $0(0.0 \%)$ & $8(2.2 \%)$ & & \\
\hline Probable frequent $\mathrm{TTH}$ & 6 & $0(0.0 \%)$ & $6(1.6 \%)$ & & \\
\hline Probable chronic TTH & 2 & $2(1.5 \%)$ & $0(0.0 \%)$ & & \\
\hline Trigeminal autonomic cephalalgias (TAC) & 11 & $4(3 \%)$ & $7(2 \%)$ & & \\
\hline Episodic cluster headache & 4 & $2(1.5 \%)$ & $2(0.5 \%)$ & & \\
\hline Episodic paroxysmal hemicrania & 3 & $2(1.5 \%)$ & $1(0.3 \%)$ & & \\
\hline Probable paroxysmal hemicrania & 3 & $0(0.0 \%)$ & $3(0.8 \%)$ & & \\
\hline Episodic SUNCT & 1 & $0(0.0 \%)$ & $1(0.3 \%)$ & & \\
\hline Other primary headache disorders & 13 & $5(3.8 \%)$ & $8(2.3 \%)$ & & \\
\hline Primary headache associated with sexual activity & 5 & $1(0.8 \%)$ & $4(1.1 \%)$ & & \\
\hline New daily persistent headache (NDPH) & 3 & $1(0.8 \%)$ & $2(0.5 \%)$ & & \\
\hline Primary stabbing headache & 2 & $1(0.8 \%)$ & $1(0.3 \%)$ & & \\
\hline Probable primary exercise headache & 1 & $1(0.8 \%)$ & $0(0.0 \%)$ & & \\
\hline Primary thunderclap headache & 1 & $0(0.0 \%)$ & $1(0.3 \%)$ & & \\
\hline Hypnic headache & 1 & $1(0.8 \%)$ & $0(0.0 \%)$ & & \\
\hline Secondary headache & 51 & $19(14.5 \%)$ & $32(8.7 \%)$ & $3: 5$ & \\
\hline Medication overuse headache $(\mathrm{MOH})$ & 14 & $7(5.3 \%)$ & $7(1.9 \%)$ & & \\
\hline Headache attributed to acute rhinosinusitis & 7 & $0(0.0 \%)$ & $7(1.9 \%)$ & & \\
\hline Persistent headache attributed to mild head injury & 5 & $3(2.3 \%)$ & $2(0.5 \%)$ & & \\
\hline Acute headache attributed to systemic viral infection & 5 & $0(0.0 \%)$ & $5(1.4 \%)$ & & \\
\hline Headache attributed to hypertensive encephalopathy & 4 & $0(0.0 \%)$ & $4(1.1 \%)$ & & \\
\hline Headache attributed to ischemic stroke & 3 & $2(1.5 \%)$ & $1(0.3 \%)$ & & \\
\hline Headache attributed to intracranial neoplasia & 2 & $2(1.5 \%)$ & $0(0.0 \%)$ & & \\
\hline Headache attributed to $\mathrm{IH}$ & 2 & $0(0.0 \%)$ & $2(0.5 \%)$ & & \\
\hline Sleep apnea headache & 1 & $0(0.0 \%)$ & $1(0.3 \%)$ & & \\
\hline Phosphodiesterase (PDE) inhibitor induced headache & 1 & $1(0.8 \%)$ & $0(0.0 \%)$ & & \\
\hline $\begin{array}{l}\text { Persistent headache attributed to moderate to severe } \\
\text { traumatic injury to the head }\end{array}$ & 1 & $1(0.8)$ & $0(0)$ & & \\
\hline Headache attributed to TIA & 1 & $1(0.8 \%)$ & $0(0.0 \%)$ & & \\
\hline
\end{tabular}


Table 3 Frequency of headache subtypes between male and female (Continued)

\begin{tabular}{|c|c|c|c|c|c|}
\hline Headache subtypes & Total & Males $(N=131)$ & Females $(N=369)$ & Male:female ratio & $P$ value \\
\hline Headache attributed to non-traumatic acute ASDH & 1 & $1(0.8 \%)$ & $0(0.0 \%)$ & & \\
\hline Headache attributed to hypothyroidism & 1 & $0(0.0 \%)$ & $1(0.3 \%)$ & & \\
\hline Headache attributed to GCA & 1 & $1(0.8 \%)$ & $0(0.0 \%)$ & & \\
\hline Headache attributed to CVT & 1 & $0(0.0 \%)$ & $1(0.3 \%)$ & & \\
\hline Headache attributed to acute glaucoma & 1 & $0(0.0 \%)$ & $1(0.3 \%)$ & & \\
\hline Painful cranial neuropathy & 4 & $2(1.5 \%)$ & $2(0.5 \%)$ & $1: 1$ & \\
\hline Classical TN purely paroxysmal & 4 & $2(1.5 \%)$ & $2(0.5 \%)$ & & \\
\hline Headache course & 500 & 131 & 369 & $1: 3$ & \\
\hline Episodic headache & $381(76.2 \%)$ & $91(69.5 \%)$ & $290(78.6 \%)$ & & \\
\hline Chronic headache & $119(23.8 \%)$ & $40(30.5 \%)$ & 79 (21.4\%) & & 0.035 \\
\hline Overlap of headache disorders & & & & & 0.06 \\
\hline Migraine and TTH & 23 & $2(1.5)$ & $21(5.7)$ & & \\
\hline Chronic migraine and $\mathrm{MOH}$ & 64 & $25(5)$ & $39(7.8)$ & & \\
\hline Chronic $\mathrm{TTH}$ and $\mathrm{MOH}$ & 44 & $13(2.6)$ & $31(6.2)$ & & \\
\hline Posttraumatic migraine & & $2(1.5)$ & $0(0)$ & & \\
\hline Migraine and headache due to sexual activity & 1 & $0(0)$ & $1(0.2)$ & & \\
\hline
\end{tabular}

ASDH acute subdural hematoma, CVT cerebral venous thrombosis, GCA giant cell arteritis', IIH idiopathic intracranial hypertension, $M O H$ medication overuse headache, PT pericranial tenderness, SUNCT short-lasting unilateral neuralgiform headache attacks with conjunctival injection and tearing, TIA transient ischemic attack, TN trigeminal neuralgia, $T H H$ tension-type headache

In our series, we found only $0.8 \%$ of the participants corresponds to painful cranial neuropathy namely trigeminal neuralgia, which is low frequency in comparison to Pedraza and colleagues [25] who reported that about $4 \%$ of the patients' headaches corresponded to cranial neuralgias while Felício and colleagues [27] reported that $2.6 \%$ of the participants suffer from cranial neuralgias. This difference may be explained by the painful cranial neuralgias particularly trigeminal neuralgia $(\mathrm{TN})$ which is a relatively rare condition with a lifetime prevalence of up to $0.3 \%$ [30], and most patients with $\mathrm{TN}$ consulted their dentist first.

As in previous studies $[12,19,31]$, we found a low frequency $(10.2 \%)$ of secondary headache. Among the patients with secondary headache, we found that the percent of $\mathrm{MOH}$ was $5.3 \%$ of total headache participants and $27.5 \%$ of the patients with secondary headache, a finding confirmed by previous studies [25, 32]. However, other studies reported higher frequency of secondary headaches ranging from 22.1 to $42 \%$ in which participants were selected from the emergency departments [33-36] because most of the emergency room (ER) doctors recognize headache as a disease with underlying somatic reasons, and some racial, regional, selection bias may contribute to these differences.

In this work, we found that headache attributed to cranial and/or cervical vascular disorder (group 6 of ICHDIII) which had been rarely observed (1.4\%), and this may be due to the patients with cerebrovascular events, mostly coming to the emergency room (ER), and headache as a symptom may not attract the attention of the ER doctors.

We found women's dominance in primary headache, particularly migraine because of the well-established hormone influence in migraine [37]. The percent of female participants was $73.8 \%$ of the total number of the patients with male to female ratio of 1:2.3 which is in line with worldwide prevalence data from the 2015 Global Burden of Disease Study [38] showing that migraine is two to three times more prevalent in women than in men. Okumura and colleagues [34] reported that migraine about 3 times higher rate was observed in female than in male patients.

In the current study, we found that male to female ratio for TTH is 1:5 which indicates that women are more prone to TTH than in men, and this is in line with the previous studies that have reported that tension-type headache is more frequently seen in women with male to female ratio of 1:6 [39-41]. In contrast to El-Sherbiny and colleagues [8] who reported that male to female ratio for TTH was 2:3, Stovner and colleagues [42] observed that male to female ratio for TTH was 4:5 which is lower than our results as most of our series are females $(73.8 \%)$ who consists about three fourths of the total number of the participants, and women are more likely to seek medical advice.

We found that episodic migraine was found in $40.6 \%$ of the total number of headache patients, chronic migraine in $10 \%$, episodic TTH in $29.2 \%$ of the total number of headache participants, chronic TTH in $4.4 \%$, and 
episodic cluster headache in $0.8 \%$ of the total number of headache participants, and this in agreement with previous study which reported that episodic migraine was present in $35.3 \%$, chronic migraine in $3.9 \%$, episodic TTH in $45.3 \%$, chronic TTH in $5.6 \%$, and cluster headache in $3.4 \%$ [8]. Like previous studies [8, 43], we also found that primary headache disorders, especially, migraine is more common in urban areas.

This study is a cross-sectional study and not a population-based survey; moreover, patients with unclassified headache disorders (group 14) were excluded from this study; therefore, the data cannot be used to accurately estimate the prevalence of primary headaches, and epidemiological studies will be needed. Our data based on clinical background including Arabic version of headache questionnaire and brain imaging studies were not routinely done for all patients, and finally, we did not do any anxiety or depression scale for patients with TTH to investigate the underlying anxiety or depression. In spite of these limitations, the present study has shown the frequency and characteristics of different headache disorders according to ICHD-III.

\section{Conclusion}

This study is among the few studies that characterize the headache patients by using the Arabic version of headache questionnaire according to the third edition of ICHD-III in Sohag Governorate, Egypt.

\section{Abbreviations}

ASDH: Acute subdural hematoma; CM: Chronic migraine; CT: Computed tomography scan; CTTH: Chronic tension-type headache; CVT: Cerebral venous thrombosis; EMR: Eastern Mediterranean Region; ER: Emergency room; GCA: Giant cell arteritis; ICHD-III: The third edition of the International Classification of Headache Disorders; $\| \mathrm{H}$ : Idiopathic intracranial hypertension; ISCED: The International Standard Classification of Education; $\mathrm{MOH}$ : Medication overuse headache; MRI: Magnetic resonance imaging; NDPH: New daily persistent headache; PT: Pericranial tenderness; SPSS: Statistical Package for the Social Sciences for window; SUNA: Chronic short-lasting unilateral neuralgiform headache attacks with cranial autonomic symptoms; SUNCT: Short-lasting unilateral neuralgiform headache attacks with conjunctival injection and tearing; TACs: Trigeminal autonomic cephalgias; TIA: Transient ischemic attack; TN: Trigeminal neuralgia; TTH: Tension type of headache
}

\section{Acknowledgements}

Not applicable

\section{Author's contributions}

$A A B$, as a single author, is solely responsible to the design and implementation of the research, to the analysis of the results, and to the writing and reviewing of the manuscript. The author read and approved the final manuscript.

\section{Funding}

None

Availability of data and materials

The data set of this work is available.

\section{Ethics approval and consent to participate}

The study was approved by local ethical committee in Faculty of Medicine, Sohag University, in March 2018. (The committee's reference number is not available.)

Informed written consent was obtained from all patients for participation and publication of this study.

\section{Consent for publication}

Not applicable

\section{Competing interests}

There were no financial or non-financial conflicts of interest.

Received: 9 June 2020 Accepted: 12 January 2021

Published online: 01 February 2021

\section{References}

1. Stovner L, Hagen K, Jensen R, Katsarava Z, Lipton R, Scher A, et al. The global burden of headache: a documentation of headache prevalence and disability worldwide. Cephalalgia. 2007:27(3):193-210.

2. Steiner TJ, Birbeck GL, Jensen RH, Katsarava Z, Stovner LJ, Martelletti $P$. Headache disorders are third cause of disability worldwide. J Headache Pain. 2015;16:58

3. Selekler HM, Gökmen G, Alvur TM, Steiner TJ. Productivity losses attributable to headache, and their attempted recovery, in a heavy-manufacturing workforce in Turkey: implications for employers and politicians. J Headache Pain. 2015;16(1):96

4. Grande RB, Aaseth K, Gulbrandsen P, Lundqvist C, Russell MB. Prevalence of primary chronic headache in a population-based sample of 30-to 44-yearold persons. Neuroepidemiology. 2008;30(2):76-83.

5. Aaseth K, Grande R, Kvárner K, Gulbrandsen P, Lundqvist C, Russell M. Prevalence of secondary chronic headaches in a population-based sample of 30-44-year-old persons. The Akershus study of chronic headache. Cephalalgia. 2008;28(7):705-13.

6. Woldeamanuel YW, Cowan RP. Migraine affects 1 in 10 people worldwide featuring recent rise: a systematic review and meta-analysis of communitybased studies involving 6 million participants. J Neurol Sci. 2017;372:307-15.

7. Vosoughi K, Stovner L, Steiner TJ, Moradi-Lakeh M, Fereshtehnejad S-M, Farzadfar $F$, et al. The burden of headache disorders in the Eastern Mediterranean Region, 1990-2016: findings from the Global Burden of Disease study 2016. J Headache Pain. 2019;20(1):40.

8. El-Sherbiny NA, Masoud M, Shalaby NM, Shehata HS. Prevalence of primary headache disorders in Fayoum Governorate, Egypt. J Headache Pain. 2015; 16(1):85.

9. Rajeh SA, Awada A, Bademosi O, Ogunniyi A. The prevalence of migraine and tension headache in Saudi Arabia: a community-based study. Eur J Neurol. 1997:4(5):502-6.

10. Bener A. Frequency of headache and migraine in Qatar. Neuroepidemiology. 2006;27(2):61-6.

11. Organization WH. Atlas of headache disorders and resources in the world 2011. Geneva: World Health Organisation; 2011.

12. Dong Z, Di H, Dai W, Liang J, Pan M, Zhang M, et al. Application of ICHD-II criteria in a headache clinic of China. PLoS One 2012;7(12):e50898.

13. Headache Classification Committee of the International Headache Society (IHS). The International Classification of Headache Disorders, 3rd edition. Cephalalgia. 2018;38:1-211.

14. Kandil M, Hamed S, Fadel K, Youssef A, Abd El Hamed M, KJJNN M. Epidemiology of tension-type headache (TTH) in Assuit Governorate, Egypt. J Neurol Neurosci. 2014;5(1):2.

15. CAPMAS - Central Agency for mobilization and Statistics. Egypt in Figures 2015. CAPMAS. 2015. from: https://article.wn.com/view/2015/03/02/Egypt in_Figures_2015_CAPMAS_Central_Agency_for_mobilization/.

16. Schneider SL. The international standard classification of education 2011. Class Stratif Anal. 2013:365-79.

17. El-Sherbiny NA, Shehata HS, Amer H, Elmazny A, Masoud M, Helmy H, et al. Development and validation of an Arabic-language headache questionnaire for population-based surveys. J Pain Res. 2017;10:1289.

18. Saylor D, Steiner TJ. The global burden of headache. Semin Neurol. 2018; 38(2):182-90. 
19. Guerrero ÁL, Rojo E, Herrero S, Neri MJ, Bautista L, Peñas ML, et al. Characteristics of the first 1000 headaches in an outpatient headache clinic registry. Headache. 2011;51(2):226-31.

20. Wang SJ, Chung CS, Chankrachang S, Ravishankar K, Merican JS, Salazar G, et al. Migraine disability awareness campaign in Asia: migraine assessment for prophylaxis. Headache. 2008:48(9):1356-65.

21. Wang Y, Zhou J, Fan X, Li X, Ran L, Tan G, et al. Classification and clinical features of headache patients: an outpatient clinic study from China. J Headache Pain. 2011;12(5):561-7.

22. Gesztelyi G, Bereczki D. Primary headaches in an outpatient neurology headache clinic in East Hungary. Eur J Neurol. 2004;11(6):389-95.

23. Murtaza M, Kisat M, Daniel H, Sonawalla AB. Classification and clinical features of headache disorders in Pakistan: a retrospective review of clinical data. PLoS One. 2009;4(6):e5827.

24. Goldstein J, Camargo C Jr, Pelletier A, Edlow J. Headache in United States emergency departments: demographics, work-up and frequency of pathological diagnoses. Cephalalgia. 2006;26(6):684-90

25. Pedraza M, Mulero P, Ruíz M, de la Cruz C, Herrero S, Guerrero A. Characteristics of the first 2000 patients registered in a specialist headache clinic. Neurología (English Edition). 2015;30(4):208-13.

26. Silva AA, Jr., Tavares RM, Lara RP, Faleiros BE, Gomez RS, Teixeira AL. Frequency of types of headache in the tertiary care center of the Hospital das Clínicas of the Universidade Federal de Minas Gerais, MG, Brazil. Revista da Associacao Medica Brasileira (1992). 2012;58(6):709-13.

27. Felício AC, Bichuetti DB, WACd S, CdO GJ, Marin LF, DdS C. Epidemiology of primary and secondary headaches in a Brazilian tertiary-care center. Arquivos Neuro-Psiquiatria. 2006;64(1):41-4.

28. Dowson AJ. Analysis of the patients attending a specialist UK headache clinic over a 3-year period. Headache. 2003;43(1):14-8.

29. Tuğba T, Serap Ü, Esra O, Özlem C, Ufuk E. Features of stabbing, cough, exertional and sexual headaches in a Turkish population of headache patients. J Clin Neurosci. 2008;15(7):774-7.

30. Mueller D, Obermann M, Yoon MS, Poitz F, Hansen N, Slomke MA, et al. Prevalence of trigeminal neuralgia and persistent idiopathic facial pain: a population-based study. Cephalalgia. 2011;31(15):1542-8.

31. Manzoni GC, Stovner LJ. Epidemiology of headache. Handb Clin Neurol. 2010;97:3-22.

32. Pascual J, Mateos V, Gracia M, Láinez J. Medication overuse headache in Spain. Cephalalgia. 2008;28(11):1234-6.

33. Dermitzakis EV, Georgiadis G, Rudolf J, Nikiforidou D, Kyriakidis P, Gravas I, et al. Headache patients in the emergency department of a Greek tertiary care hospital. J Headache Pain. 2010;11(2):123.

34. Okumura T, Tanno S, Ohhira M, Tanno S, Nozu T. Characteristics in patients with headache in an outpatient clinic in Japan. Asia Pac Fam Med. 2010; $9(1): 10$.

35. Relja G, Granato A, Capozzoli F, Maggiore C, Catalan M, Pizzolato G, et al. Nontraumatic headache in the emergency department: a survey in the province of Trieste. J Headache Pain. 2005;6(4):298-300.

36. Friedman BW, Hochberg ML, Esses D, Grosberg B, Corbo J, Toosi B, et al. Applying the International Classification of Headache Disorders to the emergency department: an assessment of reproducibility and the frequency with which a unique diagnosis can be assigned to every acute headache presentation. Ann Emerg Med. 2007;49(4):409-419, 19.e1-9.

37. Bolay H, Ozge A, Saginc P, Orekici G, Uludüz D, Yalın O, et al. Gender influences headache characteristics with increasing age in migraine patients. Cephalalgia. 2015;35(9):792-800.

38. Steiner TJ, Stovner LJ, Vos T. GBD 2015: migraine is the third cause of disability in under 50s. J Headache Pain. 2016;17(1):104.

39. Group THES. An epidemiologic study of headache in Turkey: a nationwide survey. Neurology. 1998;50(4):225.

40. Chen T, Leviton A, Edelstein S, Ellenberg J. Migraine and other diseases in women of reproductive age: the influence of smoking on observed associations. Arch Neurol. 1987;44(10):1024-8.

41. Bayraktutan OF, Demir R, Ozel L, Ozdemir G, Ertekin A. Prevalence of tension-type headache in individuals aged between 18-65 years in the eastern parts of Turkey. Eurasian J Med. 2014;46(2):78-83.

42. Global, regional, and national burden of migraine and tension-type headache, 1990-2016: a systematic analysis for the Global Burden of Disease Study 2016. Lancet Neurol. 2018;17(11):954-76.
43. Rho Yl, Chung HJ, Lee KH, Eun BL, Eun SH, Nam SO, et al. Prevalence and clinical characteristics of primary headaches among school children in South Korea: a nationwide survey. Headache. 2012;52(4):592-9.

\section{Publisher's Note}

Springer Nature remains neutral with regard to jurisdictional claims in published maps and institutional affiliations.

\section{Submit your manuscript to a SpringerOpen ${ }^{\circ}$ journal and benefit from:}

- Convenient online submission

- Rigorous peer review

- Open access: articles freely available online

- High visibility within the field

- Retaining the copyright to your article

Submit your next manuscript at $\boldsymbol{\nabla}$ springeropen.com 